\title{
Modes and Mishaps of Neuronal Migration in the Mammalian Brain
}

\author{
Christine Métin, ${ }^{1}$ Richard B. Vallee, ${ }^{2}$ Pasko Rakic, ${ }^{3}$ and Pradeep G. Bhide ${ }^{4}$ \\ ${ }^{1}$ Institut du Fer à Moulin, Inserm Unité Mixte de Recherche-S 839, 75005 Paris, France, ${ }^{2}$ Department of Pathology, Columbia University, New York, New \\ York 10032, ${ }^{3}$ Department of Neurobiology, Yale University School of Medicine, New Haven, Connecticut 06520-8001, and ${ }^{4}$ Department of Neurology, \\ Massachusetts General Hospital, Harvard Medical School, Boston, Massachusetts 02129
}

The ability of neurons to migrate to their appropriate positions in the developing brain is critical to brain architecture and function. Recent research has elucidated different modes of neuronal migration and the involvement of a host of signaling factors in orchestrating the migration, as well as vulnerabilities of this process to environmental and genetic factors. Here we discuss the role of cytoskeleton, motor proteins, and mechanisms of nuclear translocation in radial and tangential migration of neurons. We will also discuss how these and other events essential for normal migration of neurons can be disrupted by genetic and environmental factors that contribute to neurological disease in humans.

\section{Introduction}

Cell migration is a critical event in the development of the nervous system. Neurons and precursor cells migrate long distances along the dorsal-ventral and anterior-posterior axes of the nervous system during the early embryonic period. In higher vertebrates, including primates, a radial migratory pathway for dispersion of postmitotic neurons has evolved. Rakic (1972) identified radial glial cells as guides for radial neuronal migration in the primate cerebral cortex and put forward the radial unit hypothesis. This hypothesis proposed that clonally related cells migrated from the neuroepithelium toward the cortical surface along the same radial glial fascicle, producing a radial column of cells related by birth (Rakic, 1988).

Later studies showed that some clonally related cells dispersed widely, rather than remaining associated with a single radial glial fascicle (Walsh and Cepko, 1992), and that postmitotic neurons as well as precursor cells migrated tangentially across radial glial fascicles in the developing cerebral cortex (Fishell et al., 1993; O'Rourke et al., 1997). More recently, it was discovered that virtually all interneurons of the cerebral cortex, $\sim 20-35 \%$ of all cortical neurons in rodents, are produced in the ganglionic eminence of the basal forebrain and arrive in the cortex by a ventralto-dorsal, tangential migratory pathway independent of radial glial guides (de Carlos et al., 1996; Anderson et al., 1997; Tamamaki et al., 1997). In primates, including humans, although many interneurons are produced in the enlarged subventricular zone of the cerebral cortex, the majority migrate from the ganglionic eminence (Letinic et al., 2002; Petanjek et al., 2008a,b). These observations have led to current concepts of cell migration in the

Received Aug. 8, 2008; revised Aug. 29, 2008; accepted Sept. 3, 2008

Correspondence should be addressed to Dr. Pradeep G. Bhide, Developmental Neurobiology, Massachusetts General Hospital, 149 13th Street, Charlestown, MA 02129. E-mail: bhide@helix.mgh.harvard.edu. D01:10.1523/JNEUROSCI.3860-08.2008

Copyright $\odot 2008$ Society for Neuroscience $\quad 0270-6474 / 08 / 2811746-07 \$ 15.00 / 0$ developing vertebrate nervous system that include both radial and tangential migration of postmitotic neurons.

A number of genes are known to regulate radial and tangential neuronal migration. The products of these genes mediate a wide range of cellular functions, including chemoattraction/repulsion, cell adhesion, cell motility, and cytoskeletal dynamics. Human neurological disorders, such as lissencephaly, cortical heterotopias, and microcephaly, that are associated with severe cognitive disabilities are attributed to genetic mutations. Accumulating evidence indicates that the products of the genes associated with these disorders mediate cellular functions critical for neuronal migration.

Much of our knowledge about the cellular functions of genes associated with neuronal migration disorders comes from the use of mutant mice and other animal models. For example, a key insight into the genetic regulation of radial neuronal migration came from the mutant mouse reeler, named for its awkward motor coordination. Cortical layers are "upside down" in the reeler mouse because of anomalous neuronal migration (Caviness and Rakic, 1978; Rakic and Caviness, 1995). Subsequent studies revealed that reelin, the product of the reeler gene, is an extracellular matrix molecule essential for radial neuron migration (Rice and Curran, 2001). Critical insights into tangential neuronal migration also came from an animal model: the homeobox gene $D l x 1$ and Dlx2 double-mutant mouse (Anderson et al., 1997). Thus, although animal models continue to make significant contributions to our understanding of the mechanisms of neuronal migration, and although the basic principles of cortical development are similar across mammalian species, there are important differences between the different species in the timing and sequence of developmental events as well as in the genetic, molecular, and cellular modifications reflecting evolutionary adaptations of considerable functional significance (Bystron et al., 2008).

Apart from genetic factors, environmental factors such as ionizing radiation, neurotransmitter imbalance, and neurotoxins 


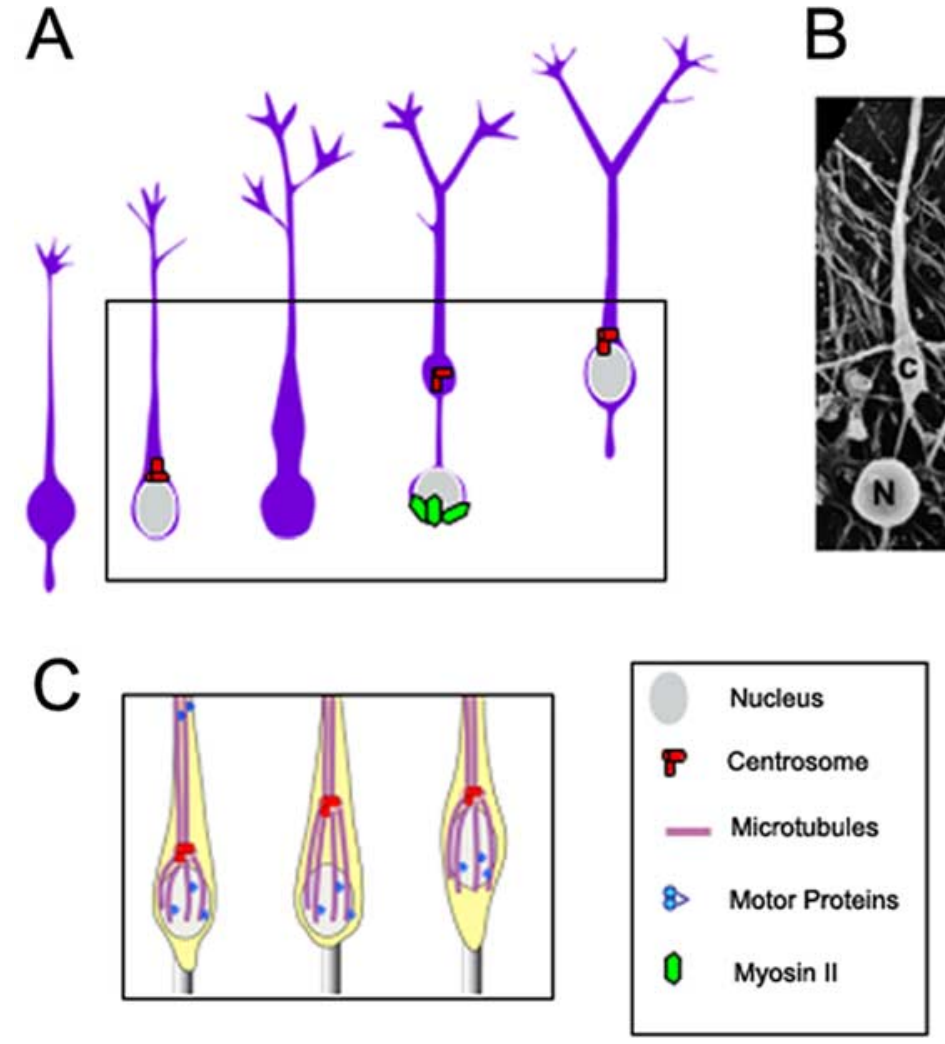

Figure 1. A, In tangentially migrating cells derived from the medial ganglionic eminence (MGE) of the basal forebrain, a centrosome (red) is located at some distance from the resting nucleus (gray). As the cell initiates migration (boxed area), the centrosome (along with Golgi apparatus, not shown) stabilizes in a rostral swelling. Nuclear movement toward the rostral swelling requires actomyosin activity (green). [This panel was modified with permission from Bellion et al. (2005), their Fig. 6.] B, A scanning electron micrograph of a migrating MGE cell showing nuclear (N)- centrosomal (c) dissociation (courtesy of J. P. Baudoin and C. Métin, Institut du Fer à Moulin, Inserm Unité Mixte de Recherche-S 839, Paris, France, used with permission). C, Classical model of centrosomal and nuclear movements in a radially migrating neuron. The centrosome (red) controls the formation of a microtubule network (purple) that surrounds the nucleus, the so-called perinuclear cage, establishing a physical link between centrioles (red) and nuclear membrane. During migration, the forward movement of centrioles leads to deformation of the perinuclear cage, which together with microtubule-associated motor complex (blue) activity pull the nucleus forward.

stop and go motions, a cyclic pattern in the complex morphological transformations exhibited by migrating MGE cells seemed plausible. When MGE cells migrate on a flat permissive substrate, they reproduce the same migratory behavior as that seen in organotypic slices. Image analysis of the migrating MGE cells showed that phases of branch outgrowth alternated with phases of branch selection. These alternating phases were correlated with nuclear movements (Bellion et al., 2005; Métin et al., 2006).

Nuclear movement of postmitotic MGE cells is a saltatory, two-step process alternating between resting and dynamic phases (Ang et al., 2003; Solecki et al., 2004; Tsai and Gleeson, 2005). During the nuclear resting phase, the centrosome moves forward, ahead of the nucleus. In MGE cells, the centrosome migrates a remarkably long distance away from the nucleus (up to $30 \mu \mathrm{m}$ ), and at the end of its forward migration, the centrosome and the Golgi apparatus fold into a single complex localized to a swelling distinct from the nuclear compartment. This rostral swelling containing the centrosome and Golgi apparatus remains connected to the larger nuclear compartment located at the rear of the cell by an extremely thin link, $\sim 10-15 \mu \mathrm{m}$ in length (Fig. $1 A, B$ ). Moreover, this phase of spatial dissociation between the nucleus and the centrosome/ Golgi complex most often corresponds to a phase of neuritic arbor remodeling.

Morphological transformations of migrating MGE cells reflect evolutionarily conserved functions of microtubule cy-

can also impair neuronal migration. The environmental factors may have a particularly significant impact in the large gyrencephalic brains of higher vertebrates that have long curvilinear migratory pathways (Rakic, 2007).

In this symposium, we discuss the role of the cytoskeleton, motor proteins, and mechanisms of nuclear translocation in radial and tangential migration of neurons. We will also discuss how these and other events can be disrupted by genetic and environmental factors that contribute to neurological disease in humans.

\section{Centrosome positioning and microtubule organization in migrating neurons}

It is now becoming clear that radial neuron migration in the cerebral cortex is associated with deployment of excitatory "projection" neurons produced in the cortical neuroepithelium, whereas cortical interneurons, produced in the medial ganglionic eminence (MGE) of the basal telencephalon, migrate to the cortex along tangential migratory pathway. Unlike radially migrating neurons, which appear to associate principally with radial glia, the MGE cells can change their cellular partners and direction of migration (Marín and Rubenstein, 2001). Accordingly, migrating MGE cells produce multiple branches as if to sample cellular partners, and select one branch to pursue a partner for migration. Because cell migration is a cyclic process involving toskeleton. In animal cells, the centrosome is a microtubule organizing center that controls microtubule polymerization, and organizes the cytoskeleton by either releasing or anchoring microtubules (Bornens, 2002). In radially migrating neurons, the centrosome controls the formation of a microtubule network that surrounds the nucleus, the so-called perinuclear cage, and establishes a physical link between centrioles and nuclear membrane (Rakic, 1971; Gregory et al., 1988; Rivas and Hatten, 1995; Rakic et al., 1996; Solecki et al., 2004; Higginbotham and Gleeson, 2007; Tsai et al., 2007). During radial migration, the forward movement of centrioles leads to deformation of the perinuclear cage. Cage elasticity together with microtubule-associated motor complex activity cooperate in pulling the nucleus forward (Fig. $1 C)$. This model fits well with the morphological transformations of radially migrating cortical neurons and may explain abnormal nucleokinesis in cortical and cerebellar neurons under pathological conditions (Tanaka et al., 2004). The pronounced dissociation between the nucleus and centrosome (Fig. 1A,B) makes perinuclear cage deformation very unlikely in tangentially migrating cortical interneurons. A more complex organization of microtubules involving dynamic and stable components, neither of which directly converges on the centrosome (Rakic et al., 1996; Umeshima et al., 2007), could exist in MGE cells. These observations raise the possibility that dynamics of additional cytoskeletal 
components may be able to generate tension forces that might also contribute to nuclear movements in MGE cells. Using blebbistatin, a specific inhibitor of nonmuscle myosin II (Straight et al., 2003), it was shown that actomyosin filaments that accumulate in the perinuclear compartment before nuclear movements play a role in controlling forward nuclear movement (Bellion et al., 2005). A similar mechanism has been described in cells of the subventricular zone that migrate tangentially to the olfactory bulb in the postnatal brain (Schaar and McConnell, 2005) and, more recently, in radially migrating cortical neurons (Tsai et al., 2007). Together these results suggest that actomyosin cytoskeleton might control nuclear movements in neurons exhibiting multiple (radial and tangential) modes of migration.

What is the role of microtubules in tangentially migrating cortical interneurons? This was addressed by examining the effect of nocodazole-induced microtubule destabilization on migration of MGE cells (Baudoin et al., 2008). Low doses of nocodazole impaired leading process morphology and cell directionality but did not affect migration speed. These results suggest a role of microtubules in the control of cell shape rather than cell motility. These findings are in agreement with observations in MGE cells from doublecortin mutant mice that show unchanged migration speed but increased branching of the neuritic arbor (Kappeler et al., 2006). Whether tangentially migrating neurons differ from radially migrating neurons with respect to cytoskeletal organization or whether tangentially and radially migrating neurons share fundamental structural and functional properties remains unclear (Higginbotham and Gleeson, 2007). Solving this question will require a more detailed picture of the organization of microtubules in tangentially migrating neurons at different phases of the migration cycle.

\section{Cellular and molecular causes of impaired migration in lissencephaly}

Lissencephaly, or "smooth brain," is a developmental disease that affects neocortical neuronal migration. Type I, or classical lissencephaly, results from sporadic mutations in the LIS1 gene, resulting in mispositioning of neurons in the neocortex and severe loss of gyri. LIS1 interacts genetically with the motor protein cytoplasmic dynein (Xiang et al., 1995). LIS1 also colocalizes with dynein at diverse subcellular sites, and common phenotypic effects are observed for LIS1 and dynein genes in neuronal and nonneuronal cells (Faulkner et al., 2000; Smith et al., 2000; Shu et al., 2004; Tanaka et al., 2004; Grabham et al., 2007). These results suggest a role for LIS1 in cytoplasmic dynein regulation and, conversely, a potential role for cytoplasmic dynein in neuronal migration and brain development.

Vector-based RNA interference (RNAi) performed using in utero electroporation in embryonic rat brain revealed LIS1 to have multiple, discrete roles in the neuronal migration pathway (Tsai et al., 2005). LIS1 RNAi blocked interkinetic nuclear migration within radial glial progenitor cells. The nuclei were arrested at random distances from the ventricular surface, and mitotic divisions were severely reduced. The latter analysis suggested that nuclei may have an absolute requirement to reach the ventricular surface to enter mitosis (Vallee and Tsai, 2006). Most neuronal precursors generated from the radial glia ascend to the subventricular zone (SVZ), where they convert to a nonmotile multipolar form. After a substantial pause in this state, the cells convert to a bipolar form and migrate outward along radial glial fibers. Conversion to the migratory form was largely blocked by LIS1 RNAi (Tsai et al., 2005), resulting in a substantial accumulation of multipolar cells in the SVZ. Finally, those few cells that did progress to the bipolar state were arrested in this condition, unable to migrate along radial glial fibers. These results together suggested a major role for LIS1 and, presumably, its regulatory target, cytoplasmic dynein, in several aspects of neuronal migration, including glial-guided radial migration.

To understand the cellular basis for these effects, in utero electroporation was used to coexpress LIS1, cytoplasmic dynein, and myosin II short hairpin RNAs along with nuclear, centrosomal, and microtubule markers (Tsai et al., 2007). Again, live analysis of migrating cells in slice culture was used to ensure that cellular and subcellular behavior faithfully reflected in vivo events. In these preparations, the centrosome advanced continuously and much farther ahead of the nucleus than is seen in dissociated neural precursor cell cultures (Fig. 2 A). The nucleus, in contrast, advanced in a very discontinuous manner, resulting in a great separation from the centrosome (Tsai et al., 2007). LIS1 and dynein RNAi each blocked centrosomal (Fig. 2A) as well as nuclear movement, whereas myosin II RNAi and the myosin II inhibitor blebbistatin each affected nuclear movement alone. These results identified cytoplasmic dynein as the motor for centrosome movement, and cytoplasmic dynein together with myosin II as the motors for nucleokinesis.

The organization and orientation of cytoskeletal elements have been difficult to define in neuronal precursors. Microtubule plus end-tracking protein GFP-EB3 imaging (Fig. $2 \mathrm{~B}$ ) was used to define the distribution of microtubules in live migrating neuronal precursors in brain slices (Tsai et al., 2007). Microtubule growth occurred at rates of $15-20 \mu \mathrm{m} / \mathrm{min}$ throughout the processes and soma of these cells. Imaging throughout the entire network of growing microtubules in cells at different stages of centrosome-to-nucleus separation provided a comprehensive map of the microtubule cytoskeleton (Fig. $2 B$ ). Unlike mature neurons, but as in other blast-like cells, microtubules were seen to emanate from the centrosome and extend radially into both leading and trailing processes. The entire microtubule cytoskeleton advanced with the centrosome at its center, and with the nucleus trailing. Dynein immunocytochemistry revealed marked accumulations of the motor protein in the nuclear region and in transient swellings located with migratory process of locomoting neurons. These results led to a model according to which cytoplasmic dynein regulated by LIS1 pulls on the microtubule network from the swellings (Vallee and Tsai, 2006; Tsai et al., 2007). The nucleus, in a behavior unique to neuronal precursor cells, advances independently by retrograde transport toward the centrosome, also pushed from behind by myosin II.

The role of LIS1 in cytoplasmic dynein regulation is poorly understood. LIS1 binds to several sites within the dynein molecule, including the motor domain (Faulkner et al., 2000; Sasaki et al., 2000; Smith et al., 2000; Tai et al., 2002). LIS1 and dynein also bind NudE and NudEL (Feng et al., 2000; Niethammer et al., 2000; Sasaki et al., 2000; Stehman et al., 2007), which also participate in the neuronal migration pathway (Feng and Walsh, 2004; Shu et al., 2004; Sasaki et al., 2005). The role of LIS1, NudE, and NudEL in dynein motor regulation is not known, although NudE and NudEL bind to subunits within the base of the dynein molecule (Stehman et al., 2007) and may serve in recruiting dynein to diverse subcellular cargoes (Guo et al., 2006; Stehman et al., 2007; Vergnolle and Taylor, 2007).

\section{Dopamine, cocaine, torsin A, and tangential migration of GABA neurons}

The role of neurotransmitters in the regulation of neurogenesis and neuronal migration is becoming increasingly evident 


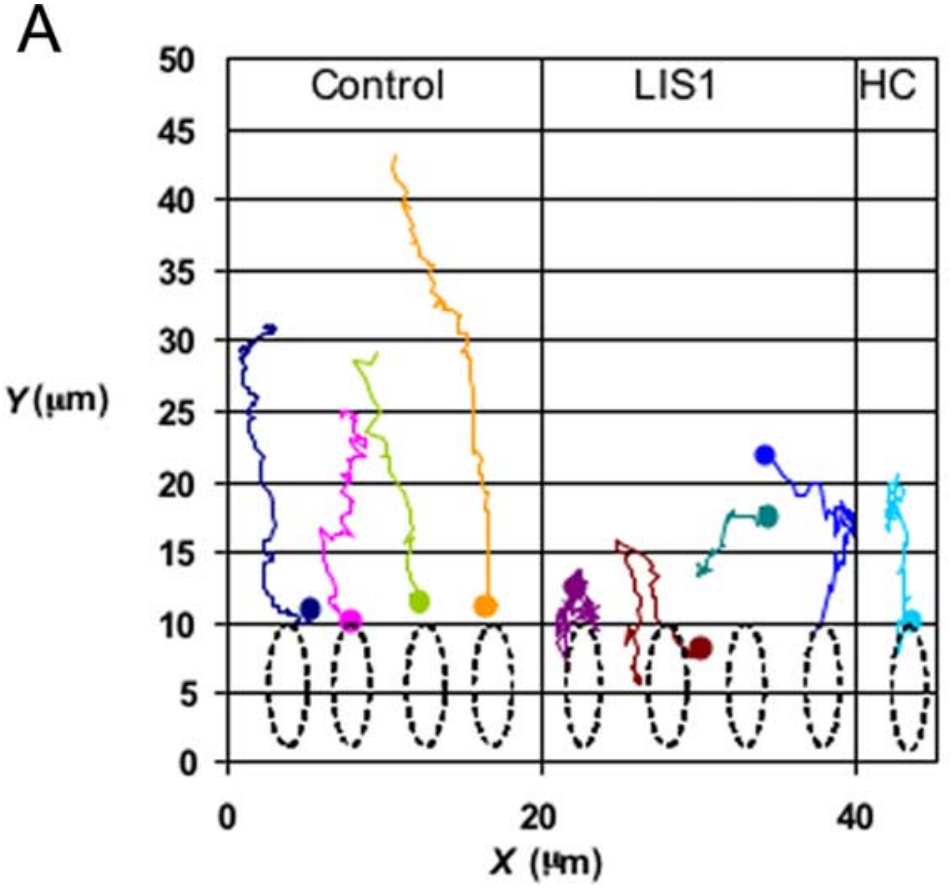

B
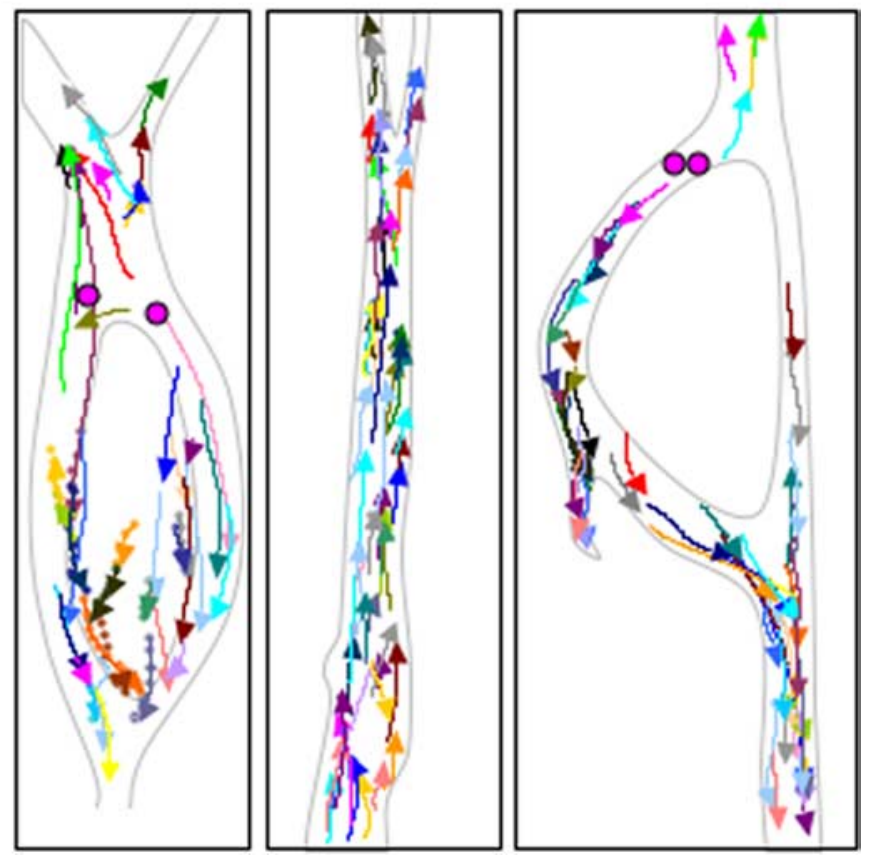

Figure 2. $\quad \boldsymbol{A}, X-Y$ tracing of centrosomal movement in radially migrating neural precursor cells monitored in live brain slice culture for up to $3 \mathrm{~h}$ (Tsai et al., 2007). Centrosomes (initial position indicated by colored dots) exhibited long-range directed travel, which was inhibited by LIS1 or cytoplasmic dynein heavy chain (HC) RNAi. B, Behavior of the microtubule plus end-tracking protein GFP-EB3 was monitored for 2 min. Traces representing all growing microtubule plus ends within a given video field (arrowheads) are shown for the cell body region, the leading "migratory" process (middle panel), and the trailing axon (seen in right panel). [Tsai et al. (2007), their Fig. 3, modified with permission].

(Komuro and Rakic, 1992; Nguyen et al., 2001; Owens and Kriegstein, 2002). As a result, insights into the consequences of impaired neurotransmitter signaling for neuronal migration in the embryonic brain are beginning to emerge. Dopamine is a neurotransmitter that can influence neurogenesis and tangential migration of cortical GABA neurons (Ohtani et al., 2003; Popolo et al., 2004; Crandall et al., 2007; McCarthy et al., 2007). Activation of the dopamine $D_{1}$-like receptor promotes, whereas that of the
$\mathrm{D}_{2}$-like receptor decreases, GABA neuron migration from the basal forebrain to the cerebral cortex (Crandall et al., 2007). Dopamine receptor activation results in redistribution of cytoskeletal elements in cultured basal forebrain neurons (Crandall et al., 2007), suggesting a molecular basis for the effects of dopamine on neuronal migration. Specifically, activation of the $\mathrm{D}_{1}$-like receptors mobilizes cytoplasmic dynein heavy chain and tubulin to cellular processes, whereas activation of the $\mathrm{D}_{2}$ receptors produces a condensation of these proteins around the nucleus (Crandall et al., 2007).

Dopamine is also a target of the psychomotor stimulant drug cocaine. Cocaine targets the dopaminergic system by binding to the dopamine transporter, decreasing dopamine reuptake and increasing extracellular dopamine levels (Ritz et al., 1987; Meyer et al., 1993). Persisting increases in extracellular dopamine result in impairment of dopamine receptor function. A number of studies confirm that fetal cocaine exposure attenuates dopamine $\mathrm{D}_{1}$ receptor signaling by uncoupling the receptor from its G-protein partner (Wang et al., 1995). This is achieved by inhibiting protein phosphatase- 1 and shifting the balance in favor of the uncoupled state of the $\mathrm{D}_{1}$ receptor (Zhen et al., 2001).

Because cocaine exposure disrupts dopamine $D_{1}$ receptor signaling and because $\mathrm{D}_{1}$ receptor activation promotes GABA neuron migration to the cerebral cortex, one can predict that exposure of the developing fetus to cocaine would decrease GABA neuron migration to the cortex. In fact, in slice preparations of brains from embryonic mice exposed to cocaine in utero, fewer cells migrated from the ganglionic eminence to the cerebral cortex (Crandall et al., 2004). Moreover, there was a significant decrease in the numbers of GABA-immunoreactive cells in the intact cerebral cortex of embryonic mice exposed to cocaine in utero (Crandall et al., 2004). These observations suggest that cocaine-induced perturbations in dopamine receptor signaling may impact migration of GABA neurons to the cerebral cortex.

The effects of in utero cocaine exposure are not limited to GABA neuron migration. It also disrupts the organization of radial glial fascicles in the embryonic mouse neocortex, leading to persistence of radial glial fascicles and an overall decrease in glial profiles (Gressens et al., 1992). Both primate and rodent models of in utero cocaine exposure report significant alterations in the histology of the embryonic and mature cerebral cortex. In the primate model, in utero cocaine exposure produced loss of cortical lamination at 2 months of age to such an extent that only the cell-poor layer I 
could be readily distinguished in conventional histological sections (Lidow et al., 2001; He and Lidow, 2004). Thus, the possibility exists that in utero cocaine exposure can impair radial neuronal migration also.

Dopamine receptor signaling mechanisms are impaired in movement disorders such as dystonia. Early-onset generalized torsion dystonia is a dominantly inherited childhood-onset movement disorder caused in most cases by a 3 bp GAG deletion in the DYT1 gene (Ozelius et al., 1997). TorsinA is the product of the DYT1 gene, and recent evidence points to an unexpected role for torsinA in the regulation of GABA neuron migration from the basal forebrain to the cerebral cortex. The majority of torsinA is localized within the nuclear envelope and the contiguous endoplasmic reticulum (Hewett et al., 2000; Kustedjo et al., 2000; Liu et al., 2003; Bragg et al., 2004), where it is thought to act as an intermediary for linking the nuclear envelope to cytoskeletal proteins via its association with SUN and nesprin proteins. Specifically, torsinA interacts with the KASH domain of nesprins (Nery et al., 2008), which span the outer nuclear membrane and link the latter to intermediate filaments in the cytoplasm (Wilhelmsen et al., 2005). In fibroblasts from torsinA knock-out mice or DYT1 dystonia patients, nesprin-3 changes its distribution to become more predominant in the endoplasmic reticulum (Nery et al., 2008). Perhaps more interestingly, fibroblasts from torsinA knock-out mice show significant impairment of nuclear polarization and cell migration in a wound-healing assay (Nery et al., 2008), suggesting a role of torsin A in nuclear translocation in migrating cells.

Because torsin A is expressed in the embryonic basal forebrain and cerebral cortex (Siegert et al., 2005; Vasudevan et al., 2006), and because it could play a role in tethering the nucleus to the cytoskeleton, it is reasonable to suggest that it plays a role in neuronal migration. In fact, recent evidence indicates significant decreases in migration of MGE cells in explant cultures obtained from torsinA knock-out mice (Bhide et al., 2008). Therefore, it appears that torsinA may influence GABA neuron migration in the embryonic brain by virtue of its dynamic interactions with nuclear envelope proteins that link the nucleus to the cytoskeleton, a key link in the mechanics of neuronal migration.

\section{Mechanisms of neuronal migration and disorders of neuronal position: a synopsis}

In the preceding sections we reviewed cellular and molecular mechanisms of neuronal migration that involve reorganization of the cytoskeleton and movement of the nucleus. We also discussed the role of motor proteins, nuclear envelope components, and neurotransmitter receptors in the regulation of the neuronal migration. A host of genetic factors are involved in the regulation of specific components of the neuronal migration process, such as progenitor proliferation, cell cycle exit, establishment of polarity, detachment from the local substrate, and rate of nuclear and somal translocation (for review, see Rakic, 2007). As a result, the precise radial and tangential deployment of cerebral cortical neurons is highly vulnerable to a large number of genetic mutations as well as various physical (e.g., ionizing radiation, ultrasonic waves, and heat), chemical (e.g., drugs and alcohol), and biological (e.g., neurotrophic viruses) agents. Disruption or even slowing down of neuronal migration may result not only in gross and obvious but also subtle abnormalities in neuronal positioning that indirectly affect the pattern of synaptic circuits (Algan and Rakic, 1997; Ang et al., 2006).

Severe malformations such as microencephaly, schizencephaly, lissencephaly, macrogyria, or polymicrogyria are to a major extent a consequence of defective migration and abnormal settling of nerve cells. Other migratory abnormalities can be revealed in the mature brain by the presence of groups or solitary ectopic neurons that have failed to reach their proper targets and are scattered within the white matter. However, in many cases the neuronal malpositioning may be subtle and cannot be detected readily by conventional histopathologic techniques. Such misplaced neurons may be involved in a variety of idiopathic neurological disorders that range from childhood epilepsy and mental retardation to autism and developmental dyslexia. Because the detection of improper position of isochronously generated neurons requires DNA labeling and/or use of transgenic animal models, not applicable to human, the subtle migratory abnormalities could be entirely missed by routine imaging of live or autopsied brains.

In conclusion, the identity, synaptic relationship and, ultimately, function of neurons in the brain depends on their proper location, which is achieved by long distance migration in the embryonic brain. In the cerebral cortex, neurons reach their final destinations via radial or tangential migratory pathways. Based on a plethora of evidence for the involvement of multiple molecules in regulation of complex cellular events essential for neuronal placement, it is now possible to propose working models of the sequence of gene expression, cascades of multiple molecular pathways, and complex cell-cell interactions that are involved in normal as well as abnormal neuronal migration (Rakic, 2007). These models show how multiple causes can produce similar cognitive disorders and how the same genetic or environmental factor can produce diverse malformations, depending on when and where the causative factors act. Thus, a new challenge is to develop methods for detection of subtle laminar and radial misplacement of neurons to determine how this deviation affects the highest cognitive functions.

\section{References}

Algan O, Rakic P (1997) Radiation-induced, lamina-specific deletion of neurons in the primate visual cortex. J Comp Neurol 381:335-352.

Anderson SA, Eisenstat DD, Shi L, Rubenstein JLR (1997) Interneuron migration from basal forebrain to neocortex: dependence on $D l x$ genes. Science 278:474-476.

Ang ES Jr, Haydar TF, Gluncic V, Rakic P (2003) Four-dimensional migratory coordinates of GABAergic interneurons in the developing mouse cortex. J Neurosci 23:5805-5815.

Ang ES Jr, Gluncic V, Duque A, Schafer ME, Rakic P (2006) Prenatal exposure to ultrasound waves impacts neuronal migration in mice. Proc Natl Acad Sci U S A 103:12903-12910.

Baudoin JP, Alvarez C, Gaspar P, Métin C (2008) Nocodazole-induced changes in microtubule dynamics impair the morphology and directionality of migrating medial ganglionic eminence cells. Dev Neurosci 30:132-143.

Bellion A, Baudoin JP, Alvarez C, Bornens M, Métin C (2005) Nucleokinesis in tangentially migrating neurons comprises two alternating phases: forward migration of the Golgi/centrosome associated with centrosome splitting and myosin contraction at the rear. J Neurosci 25:5691-5699.

Bhide PG, McCarthy DM, Sims JR, Zeng J, Li Y, Breakefield X (2008) TorsinA influences neurogenesis and neuronal migration in the embryonic brain. Soc Neurosci Abstr 34:248.10.

Bornens M (2002) Centrosome composition and microtubule anchoring mechanisms. Curr Opin Cell Biol 14:25-34.

Bragg DC, Camp SM, Kaufman CA, Wilbur JD, Boston H, Schuback DE, Hanson PI, Sena-Esteves M, Breakefield XO (2004) Perinuclear biogenesis of mutant torsin-A inclusions in cultured cells infected with tetracycline-regulated herpes simplex virus type 1 amplicon vectors. Neuroscience 125:651-661.

Bystron I, Blakemore C, Rakic P (2008) Development of the human cerebral cortex: Boulder Committee revisited. Nat Rev Neurosci 9:110-122. 
Caviness VS Jr, Rakic P (1978) Mechanisms of cortical development: a view from mutations in mice. Annu Rev Neurosci 1:297-326.

Crandall JE, Hackett HE, Tobet SA, Kosofsky BE, Bhide PG (2004) Cocaine exposure decreases GABA neuron migration from the ganglionic eminence to the cerebral cortex in embryonic mice. Cereb Cortex 14:665-675.

Crandall JE, McCarthy DM, Araki KY, Sims JR, Ren JQ, Bhide PG (2007) Dopamine receptor activation modulates GABA neuron migration from the basal forebrain to the cerebral cortex. J Neurosci 27:3813-3822.

de Carlos JA, López-Mascaraque L, Valverde F (1996) Dynamics of cell migration from the lateral ganglionic eminence in the rat. J Neurosci 16:6146-6156.

Faulkner NE, Dujardin DL, Tai CY, Vaughan KT, O'Connell CB, Wang Y, Vallee RB (2000) A role for the lissencephaly gene LIS1 in mitosis and cytoplasmic dynein function. Nat Cell Biol 2:784-791.

Feng Y, Walsh CA (2004) Mitotic spindle regulation by Ndel controls cerebral cortical size. Neuron 44:279-293.

Feng Y, Olson EC, Stukenberg PT, Flanagan LA, Kirschner MW, Walsh CA (2000) LIS1 regulates CNS lamination by interacting with mNudE, a central component of the centrosome. Neuron 28:665-679.

Fishell G, Mason CA, Hatten ME (1993) Dispersion of neural progenitors within the germinal zones of the forebrain. Nature 362:636-638.

Grabham PW, Seale GE, Bennecib M, Goldberg DJ, Vallee RB (2007) Cytoplasmic dynein and LIS1 are required for microtubule advance during growth cone remodeling and fast axonal outgrowth. J Neurosci 27:5823-5834.

Gregory WA, Edmondson JC, Hatten ME, Mason CA (1988) Cytology and neuron-glial apposition of migrating cerebellar granule cells in vitro. J Neurosci 8:1728-1738.

Gressens P, Kosofsky BE, Evrard P (1992) Cocaine-induced disturbances of corticogenesis in the developing murine brain. Neurosci Lett 140:113-116.

Guo J, Yang Z, Song W, Chen Q, Wang F, Zhang Q, Zhu X (2006) Nudel contributes to microtubule anchoring at the mother centriole and is involved in both dynein-dependent and -independent centrosomal protein assembly. Mol Biol Cell 17:680-689.

He N, Lidow MS (2004) Cerebral cortical abnormalities seen in a nonhuman primate model of prenatal cocaine exposure are not related to vasoconstriction. Neurotoxicology 25:419-432.

Hewett J, Gonzalez-Agosti C, Slater D, Ziefer P, Li S, Bergeron D, Jacoby DJ, Ozelius LJ, Ramesh V, Breakefield XO (2000) Mutant torsinA, responsible for early-onset torsion dystonia, forms membrane inclusions in cultured neural cells. Hum Mol Genet 9:1403-1413.

Higginbotham HR, Gleeson JG (2007) The centrosome in neuronal development. Trends Neurosci 30:276-283.

Kappeler C, Saillour Y, Baudoin JP, Tuy FP, Alvarez C, Houbron C, Gaspar P, Hamard G, Chelly J, Métin C, Francis F (2006) Branching and nucleokinesis defects in migrating interneurons derived from doublecortin knockout mice. Hum Mol Genet 15:1387-1400.

Komuro H, Rakic P (1992) Selective role of N-type calcium channels in neuronal migration. Science 257:806-809.

Kustedjo K, Bracey MH, Cravatt BF (2000) Torsin A and its torsion dystonia-associated mutant forms are lumenal glycoproteins that exhibit distinct subcellular localizations. J Biol Chem 275:27933-27939.

Letinic K, Zoncu R, Rakic P (2002) Origin of GABAergic neurons in the human neocortex. Nature 417:645-649.

Lidow MS, Bozian D, Song ZM (2001) Cocaine affects cerebral neocortical cytoarchitecture in primates only if administered during neocortical neuronogenesis. Brain Res Dev Brain Res 128:45-52.

Liu Z, Zolkiewska A, Zolkiewski M (2003) Characterization of human torsinA and its dystonia-associated mutant form. Biochem J 374:117-122.

Marín O, Rubenstein JL (2001) A long, remarkable journey: tangential migration in the telencephalon. Nat Rev Neurosci 2:780-790.

McCarthy D, Lueras P, Bhide PG (2007) Elevated dopamine levels during gestation produce region-specific decreases in neurogenesis and subtle deficits in neuronal numbers. Brain Res 1182:11-25.

Métin C, Baudoin JP, Rakić S, Parnavelas JG (2006) Cell and molecular mechanisms involved in the migration of cortical interneurons. Eur J Neurosci 23:894-900.

Meyer JS, Shearman LP, Collins LM, Maguire RL (1993) Cocaine binding sites in fetal rat brain: implications for prenatal cocaine action. Psychopharmacology 112:445-451.
Nery FC, Zeng J, Niland BP, Hewett J, Farley J, Irimia D, Li Y, Wiche G, Sonnenberg A, Breakefield XO (2008) TorsinA binds the KASH domain of nesprins and participates in linkage between nuclear envelope and cytoskeleton. J Cell Sci 121:3476-3486.

Nguyen L, Rigo JM, Rocher V, Belachew S, Malgrange B, Rogister B, Leprince P, Moonen G (2001) Neurotransmitters as early signals for central nervous system development. Cell Tissue Res 305:187-202.

Niethammer M, Smith DS, Ayala R, Peng J, Ko J, Lee MS, Morabito M, Tsai LH (2000) NUDEL is a novel Cdk5 substrate that associates with LIS1 and cytoplasmic dynein. Neuron 28:697-711.

Ohtani N, Goto T, Waeber C, Bhide PG (2003) Dopamine modulates cell cycle in the lateral ganglionic eminence. J Neurosci 23:2840-2850.

O’Rourke NA, Chenn A, McConnell SK (1997) Postmitotic neurons migrate tangentially in the cortical ventricular zone. Development 124:997-1005.

Owens DF, Kriegstein AR (2002) Developmental neurotransmitters? Neuron 36:989-991.

Ozelius LJ, Hewett JW, Page CE, Bressman SB, Kramer PL, Shalish C, de Leon D, Brin MF, Raymond D, Corey DP, Fahn S, Risch NJ, Buckler AJ, Gusella JF, Breakefield XO (1997) The early-onset torsion dystonia gene (DYT1) encodes an ATP-binding protein. Nat Genet 17:40-48.

Petanjek Z, Dujmovic A, Kostovic I, Esclapez M (2008a) Distinct origin of GABA-ergic neurons in forebrain of man, nonhuman primates and lower mammals. Coll Antropol 32[Suppl 1]:9-17.

Petanjek Z, Berger B, Esclapez M (2008b) Origins of cortical GABAergic neurons in the cynomolgus monkey. Cereb Cortex. Advance online publication. Retrieved October 16, 2008. doi:10.1093/cercor/bhn078

Popolo M, McCarthy DM, Bhide PG (2004) Influence of dopamine on precursor cell proliferation and differentiation in the embryonic mouse telencephalon. Dev Neurosci 26:229-244.

Rakic P (1971) Neuron-glia relationship during granule cell migration in developing cerebellar cortex. A Golgi and electronmicroscopic study in Macacus Rhesus. J Comp Neurol 141:283-312.

Rakic P (1972) Mode of cell migration to the superficial layers of fetal monkey neocortex. J Comp Neurol 145:61-83.

Rakic P (1988) Specification of cerebral cortical areas. Science 241:170-176.

Rakic P (2007) The radial edifice of cortical architecture: from neuronal silhouettes to genetic engineering. Brain Res Rev 55:204-219.

Rakic P, Caviness VS Jr (1995) Cortical development: view from neurological mutants two decades later. Neuron 14:1101-1104.

Rakic P, Knyihar-Csillik E, Csillik B (1996) Polarity of microtubule assemblies during neuronal cell migration. Proc Natl Acad Sci U S A 93:9218-9222.

Rice DS, Curran T (2001) Role of the reelin signaling pathway in central nervous system development. Annu Rev Neurosci 24:1005-1039.

Ritz MC, Lamb RJ, Goldberg SR, Kuhar MJ (1987) Cocaine receptors on dopamine transporters are related to self-administration of cocaine. Science 237:1219-1223.

Rivas RJ, Hatten ME (1995) Motility and cytoskeletal organization of migrating cerebellar granule neurons. J Neurosci 15:981-989.

Sasaki S, Shionoya A, Ishida M, Gambello MJ, Yingling J, Wynshaw-Boris A, Hirotsune S (2000) A LIS1/NUDEL/cytoplasmic dynein heavy chain complex in the developing and adult nervous system. Neuron 28:681-696.

Sasaki S, Mori D, Toyo-oka K, Chen A, Garrett-Beal L, Muramatsu M, Miyagawa S, Hiraiwa N, Yoshiki A, Wynshaw-Boris A, Hirotsune S (2005) Complete loss of Ndel1 results in neuronal migration defects and early embryonic lethality. Mol Cell Biol 25:7812-7827.

Schaar BT, McConnell SK (2005) Cytoskeletal coordination during neuronal migration. Proc Natl Acad Sci U S A 102:13652-13657.

Shu T, Ayala R, Nguyen MD, Xie Z, Gleeson JG, Tsai LH (2004) Ndell operates in a common pathway with LIS1 and cytoplasmic dynein to regulate cortical neuronal positioning. Neuron 44:263-277.

Siegert S, Bahn E, Kramer ML, Schulz-Schaeffer WJ, Hewett JW, Breakefield XO, Hedreen JC, Rostasy KM (2005) TorsinA expression is detectable in human infants as young as 4 weeks old. Brain Res Dev Brain Res 157:19-26.

Smith DS, Niethammer M, Ayala R, Zhou Y, Gambello MJ, Wynshaw-Boris A, Tsai LH (2000) Regulation of cytoplasmic dynein behaviour and microtubule organization by mammalian Lis1. Nat Cell Biol 2:767-775.

Solecki DJ, Model L, Gaetz J, Kapoor TM, Hatten ME (2004) Par6alpha 
signaling controls glial-guided neuronal migration. Nat Neurosci 7:1195-1203.

Stehman SA, Chen Y, McKenney RJ, Vallee RB (2007) NudE and NudEL are required for mitotic progression and are involved in dynein recruitment to kinetochores. J Cell Biol 178:583-594.

Straight AF, Cheung A, Limouze J, Chen I, Westwood NJ, Sellers JR, Mitchison TJ (2003) Dissecting temporal and spatial control of cytokinesis with a myosin II inhibitor. Science 299:1743-1747.

Tai CY, Dujardin DL, Faulkner NE, Vallee RB (2002) Role of dynein, dynactin, and CLIP-170 interactions in LIS1 kinetochore function. J Cell Biol 156:959-968.

Tamamaki N, Fujimori KE, Takauji R (1997) Origin and route of tangentially migrating neurons in the developing neocortical intermediate zone. J Neurosci 17:8313-8323.

Tanaka T, Serneo FF, Higgins C, Gambello MJ, Wynshaw-Boris A, Gleeson JG (2004) Lis1 and doublecortin function with dynein to mediate coupling of the nucleus to the centrosome in neuronal migration. J Cell Biol 165:709-721.

Tsai LH, Gleeson JG (2005) Nucleokinesis in neuronal migration. Neuron 46:383-388.

Tsai JW, Chen Y, Kriegstein AR, Vallee RB (2005) LIS1 RNA interference blocks neural stem cell division, morphogenesis, and motility at multiple stages. J Cell Biol 170:935-945.

Tsai JW, Bremner KH, Vallee RB (2007) Dual subcellular roles for LIS1 and dynein in radial neuronal migration in live brain tissue. Nat Neurosci 10:970-979.
Umeshima H, Hirano T, Kengaku M (2007) Microtubule-based nuclear movement occurs independently of centrosome positioning in migrating neurons. Proc Natl Acad Sci U S A 104:16182-16187.

Vallee RB, Tsai JW (2006) The cellular roles of the lissencephaly gene LIS1, and what they tell us about brain development. Genes Dev 20:1384-1393.

Vasudevan A, Breakefield XO, Bhide PG (2006) Developmental patterns of torsinA and torsinB expression. Brain Res 1073-1074:139-145.

Vergnolle MA, Taylor SS (2007) Cenp-F links kinetochores to Ndel1/Nde1/ Lis1/dynein microtubule motor complexes. Curr Biol 17:1173-1179.

Walsh C, Cepko CL (1992) Widespread dispersion of neuronal clones across functional regions of the cerebral cortex. Science 255:434-440.

Wang HY, Runyan S, Yadin E, Friedman E (1995) Prenatal exposure to cocaine selectively reduces D1 dopamine receptor-mediated activation of striatal Gs proteins. J Pharmacol Exp Ther 273:492-498.

Wilhelmsen K, Litjens SH, Kuikman I, Tshimbalanga N, Janssen H, van den Bout I, Raymond K, Sonnenberg A (2005) Nesprin-3, a novel outer nuclear membrane protein, associates with the cytoskeletal linker protein plectin. J Cell Biol 171:799-810.

Xiang X, Osmani AH, Osmani SA, Xin M, Morris NR (1995) NudF, a nuclear migration gene in Aspergillus nidulans, is similar to the human LIS-1 gene required for neuronal migration. Mol Biol Cell 6:297-310.

Zhen X, Torres C, Wang HY, Friedman E (2001) Prenatal exposure to cocaine disrupts D1A dopamine receptor function via selective inhibition of protein phosphatase 1 pathway in rabbit frontal cortex. J Neurosci 21: 9160-9167. 